\title{
Mickey Mouse sign and Humming Bird sign: Diagnostic clue of Progressive Supranuclear Palsy
}

\author{
Sreeramulu D', Quraishi SMS², Harish PV³, Theja $\mathbf{C R}^{4}$ \\ ${ }^{1}$ Dr. Diguvinti Sreeramulu, MD Medicine, Associate Professor, ${ }^{2}$ Dr SM Saifullah Quraishi MD Medicine, Assistant \\ professor, ${ }^{3}$ Dr. PV Harish, Post Graduate student, Medicine, ${ }^{4}$ Dr C Ravi Theja, Post Graduate student, Medicine. All are \\ affiliated to Kurnool Medical College Kurnool, Andhra Pradesh, India
}

\begin{abstract}
Progressive supranuclear palsy is a neurodegenerative disorder. The cause of PSP is unknown. It is under diagnosed by physician and neurologist. Clinical feature of PSP resemble with parkinsonism, carticobasal degeneration, multiple system atrophy and multi infarct state. Due to common clinical feature with Parkinsonism, carticobasal degeneration, multiple system atrophy neuroimaging that can help to diagnose PSP. MRI play pivotal role in confirming the diagnosis.
\end{abstract}

Keywords: Parkinsonism, Supranuclear palsy, Mickey Mouse sign, Retrocollis, Humming Bird sign

\section{Case Report}

The patient is a 50 years female presented with frequent fall and loss of bladder control in the form of frequency, urgency and incontinence. There was additional messy eating because of inability to look down at the plate. There were no tremor dysphagia and motor weakness. The symptoms become worst 6 months before presenting to our facility. Examination in our facility reveals bradykinesia, decrease fine motor skills and hypophonia. Her gait was characterized by not swinging of arm with retrocollis. Her face was blank mask like and speech was slurred and monotonous. There was defective pronunciation of consonant and loss of prosody Glabella and palmomental reflex were present. She was also having predominant axial rigidity, vertical gaze palsy with preservation of lateral eye movement and mild cognitive impairment [mainly memory and calculation].There were no abnormality found in cranial nerve and sensory system. Cerebellar feature were absent. Her MRI brain [figure-1] showed atrophy of mid brain with beaking along its posterior surfaces [humming bird sign] confirming the diagnosis of progressive supranuclear palsy. Patient was treated with levodopa/carbidopa without improvement in clinical feature and latter patient was treated with pramipexole [dopamine agonist] and selegiline [monoamine oxidase inhibitor] were added. However there was no appreciable improvement in patient condition.

Manuscript received: $17^{\text {st }}$ July 2014

Reviewed: $20^{\text {th }}$ July 2014

Author Corrected: $16^{\text {th }}$ Aug 2014

Accepted for Publication: $21^{\text {st }}$ Aug 2014

\section{Discussion}

Progressive supranuclear palsy is neurodegenerative disease of middle and older age group. Prevalence of disease is 1.39 per 100000 population [1]. This figure is underestimated as many patients with PSP is not diagnosed or misdiagnosed as idiopathic Parkinsonism disease. Incidence of PSP is increase with age 1.7 at 5059 years, 14.7at 80-99 [2]. Males are more commonly affected then female [3]. PSP is a sporadic disease but few familial cases have been reported [4]. Cause of PSP is not known exposure to toxin or viral infection is proposed aetiology without any concrete evidence [5].

Postural instability supranuclear gaze palsy, rigidity, abnormal posture of the neck retrocolis, frontral lobe symptoms, and dementia are main feature of PSP. Pyramidal and cerebral feature are variable. Postural instability and falls is common presenting feature. In our case patient presented with frequent fall with slow unsteady gait, symmetrical bradykinesia with axial rigidity these feature were unresponsive to levo dopa therapy. Dysarthria and dysphagia is early clinical feature of PSP. Frontal lobe feature are early in course of disease [6].

In PSP Supranuclear vertical gaze palsy may be followed by horizontal gaze palsy. Supanuclear gaze palsy may occasionally be absent but when present vertical gaze will be affected first than letter horizontal gaze will be affected [7] . Limitation of downward gaze is more specific for PSP because with age some upward 
restriction is common and limitation of upward gaze is more common then limitation of downward gaze in neurodegenerative disorder [8]. Disorder like dementia with lewy body, corticobasal degeneration, vascular parkinsonism, creutzfeldt-jakob disease and whipple disease have first horizontal gaze palsy $[9,10,11]$. Dysfunction of voluntary eye lid movement is characteristic feature of PSP, this include reduce blinking, blepharospasm and slowing of eye opening and closing are late feature [12].

Motor system mainly axial muscle is more affected then the limb muscle. In axial muscle neck muscle is more involved then trunk muscles [13]. Pyramidal signs can be seen in one third of patient. dysarthria is an early feature and it is of mixed type with combination of hypokinetic, spastic and ataxic component [14]. PSP is a clinical diagnosis but some investigation may support or exclude related diagnosis. Electro-oculographic recording can differentiate PSP from related disorders absent orbicularis oculi response to median nerve stimulation or acoustic startling stimuli are suggestive of PSP [15].

MRI in mid- sagittal $T_{2}$ weighted MRI shows selective atrophy of mid brain tegmentum with relative preservation of pons it appears like head and body of humming bird this is known as humming bird sign or the king penguin sign [figure-1]. Axial $T_{2}$ MRI shows reduction of anterior-posterior diameter and thinning of cerebral peduncle give appearance like mickey-mouse sign [figure-2] [16, 17].

MRI mainly help to exclude other diagnosis like multiple system atrophy [atrophy of pons middle cerebral puduncle and cerebellum], corticobasal degeneration [asymmetric atrophy of parietal area] and multi infarct dementia.

\section{Conclusion}

Many cases of PSP are misdiagnosed with characteristic neuroradiology feature can help in diagnosis of PSP. At present PSP is not having specific treatment. But dopaminergic replacement therapy may give transient relief in symptoms. There is severe loss of cholinergic neurons in brain in PSP but cholinergic agonist or cholinesterase inhibitors are not useful. Supportive treatment in the form of antidepressant helps in emotional instability, depression.

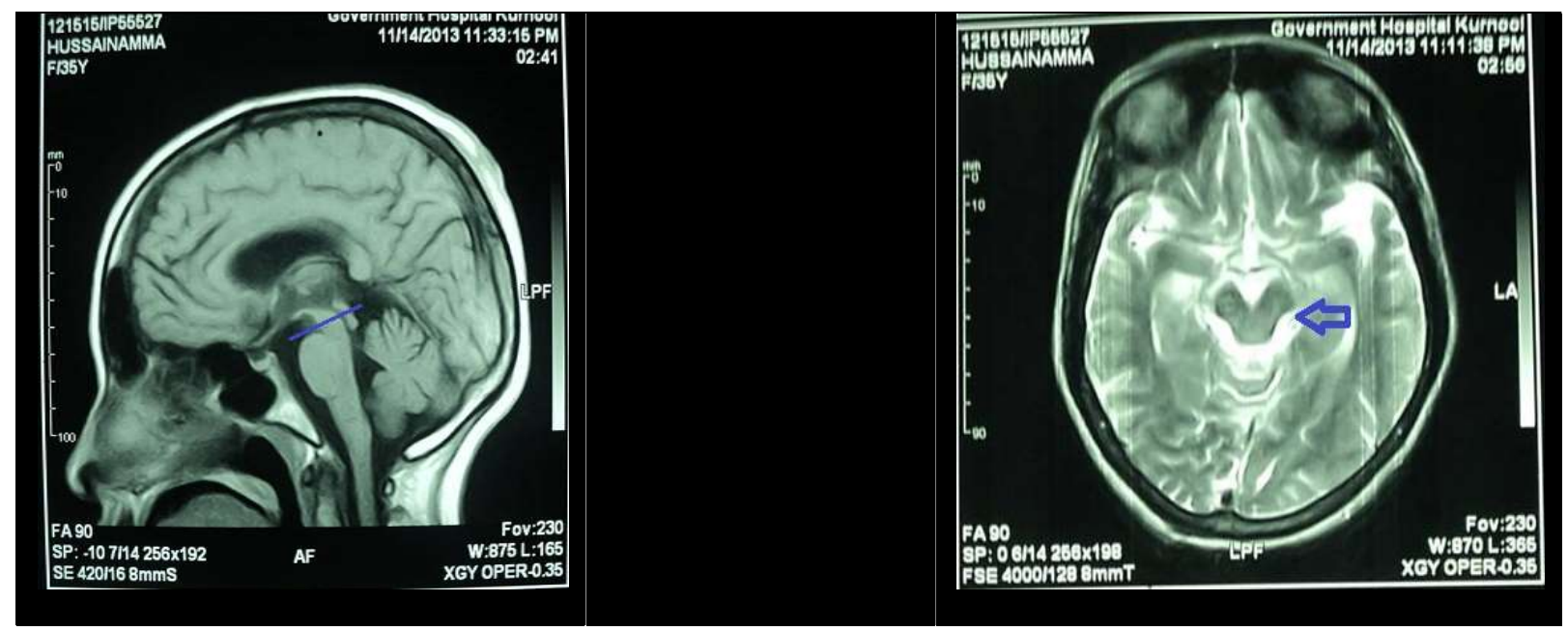

Figure 1: Humming Bird Sign

T2-weighted MRI image of the brain Showing the selective atrophy of midbrain with preservation of pons (divided by the black line).The atrophy of the midbrain tegmentum results in the concavity forming the silhouette of the head of the 'Hummingbird' or the 'King Penguin' This feature is called the hummingbird sign
Figure2: Mickey-Mouse Sign Axial

T2 weighted image showing atrophy of midbrain tegmentum and thinning of cerebral peduncles resulting in concavity of as micky mouse sing 


\section{References}

1. Golbe Li, Davis PH, Schoenberg BS, Duvoisin RC. Prevalence and natural history of progressive supranuclear palsy. Neurology. 1988 Jul;38(7):1031-4.

2. Golbe LI, Davis PH, Schoenberg BS, Duvoisin RC. Prevalence and natural history of progressive supranuclear palsy. Neurology. 1988 Jul;38(7):1031-4

3. Bower JH, Maraganore DM, McDonnell SK, Rocca W.A. Incidence of progressive supranuclear palsy and multiple system atrophy in Olmsted County Minnesota, 1976 to 1990. Neurology. 1997 Nov;49(5):1284-1288.

4. Santacruz P, Uttl B, Litvan I, Grafman J. Progressive supranuclear palsy: a survey of disease course. Neurology. 1998 Jun;50(6):1637-47.

5. Ohara S, Kondo K, Morita H, maruyama K, Ikeda S, Yanagisawa N. Progressive supranuclear palsy-like syndrome in two siblings of a consanguineous marriage. Neurology. 1992 May;42(5):1009-14

6. Davis PH, Golbe LI, Duvoisin RC, sehoenberg BS. Risk factors for progressive supranuclear palsy. Neurology. 1988 Oct;38(10):1546-52

7. KR, Pearce RK Natural history of progressive supranuclear palsy (Steele-Richardson-Olszewski syndrome) and clinical predictors of survival: a clinicopathological study. J Neurol Neurosurg Psychiatry 1996; 60:615-620.

8. Daniel SE, De Bruin VMS, Lees AJ .The clinical and pathological spectrum of Steele-Richardson-Olszewski syndrome (progressive supranuclear palsy): a reappraisal. Brain 1995;118 (3):759-770

9. Colosimo C, Albanese A, Hughes AJ, De bruin VMS, Lees AJ. Some specific clinical features differentiate multiple system atrophy (striatonigral variety) from Parkinson's disease. Arch Neurol 1995;52(3):294-298.
10. De Bruin VM, Lees AJ, Daniel SE. Diffuse Lewy body disease presenting with supranuclear gaze palsy, parkinsonism, and dementia: a case report. Mov Disord. 1992 Oct;7(4):355-8.

11. Amarenco P, Roullet E, Hannoun L, R Marteau. Progressive supranuclear palsy as the sole manifestation of systemic Whipple's disease treated with pefloxacine (letter). J Neurol Neurosurg Psychiatry. 1991 Dec;54(12):1121-2..

12. De Bruin VM, Lees AJ. Subcortical neurofibrillary degeneration presenting as Steele-Richardson-Olszewski and other related syndromes: a review of 90 pathologically verified cases. Mov Disord 1994; 9(4):381-389.

13. Troost B, Daroff R. The ocular motor defects in progressive supranuclear palsy. Ann Neurol 1977; 2(5):397-403.

14. Tanigawa A, Komiyama A, Hasegawa O. Truncal muscle tonus in progressive supranuclear palsy. J Neurol Neurosurg Psychiatry. 1998 Feb;64(2):190-6

15. Kluin KJ, Foster NL, Berent S, Gilman S. Perceptual analysis of speech disorders in progressive supranuclear palsy. Neurology. 1993 Mar;43(3 Pt 1):563-6.

16. Vidailhet M, Rothwell JC, Thompson PD,AJ lees, CD Marsden.The auditory startle response in the SteeleRichardson-Olszewski syndrome and Parkinson's disease. Brain. 1992 Aug;115 ( Pt 4):1181-92

17. Kato N, Arai K, Hattori T. Study of rostral midbrain atrophy in progressive supranuclear palsy. J Neurol Sci. 2003 Jun 15;210(1-2):57-60

18. Slowinski J, Imamura A, Uitti RJ, RA Pooley, AJ Strongosky, DW Dickson, DF Broderick, ZK Wszolek. MR imaging of brainstem atrophy in progressive supranuclear palsy J Neurol. 2008 Jan;255(1):37-44.

\section{How to cite this article?}

Sreeramulu D, Quraishi SMS, Harish PV, Theja CR. Mickey Mouse sign and Humming Bird sign: Diagnostic clue of Progressive Supranuclear Palsy Int J Med Res Rev 2014;2(5):504- 506. doi:10.17511/ijmrr.2014.i05.16 